OPEN ACCESS

Edited by:

Fernando Gomollón,

University of Zaragoza, Spain

Reviewed by:

Raja Atreya

University Hospital Erlangen, Germany

Santiago García López, Hospital Universitario Miguel

Servet, Spain

*Correspondence:

Parambir Dulai

psdulai@ucsd.edu

Specialty section: This article was submitted to

Gastroenterology

a section of the journal

Frontiers in Medicine

Received: 21 September 2019 Accepted: 21 February 2020

Published: 02 April 2020

Citation:

Meserve $J$ and Dulai P (2020) Predicting Response to Vedolizumab in Inflammatory Bowel Disease.

Front. Med. 7:76.

doi: 10.3389/fmed.2020.00076

\section{Predicting Response to Vedolizumab in Inflammatory Bowel Disease}

\author{
Joseph Meserve and Parambir Dulai* \\ Department of Gastroenterology, University of California, San Diego, San Diego, CA, United States
}

Vedolizumab is known to be safe, well-tolerated, and effective. However, as personalization becomes an increasingly important aspect of IBD care and in lieu of guidelines to inform clinicians on positioning of biologics, there is a need to reliably predict response to inform patient preferences and shared decision-making. Recent data from clinical trials and real-world evidence have elucidated predictors of clinical and endoscopic response while providing the framework to establish predictive models. Current models are able to predict that those patients with less severe disease, without prior biologic exposure and who demonstrate early response to VDZ have the highest rates of durable clinical and endoscopic response and remission. When incorporating these models into clinical practice, clinicians will be able to identify those patients who are likely to respond before drug initiation as well as early non-responders and response latency after initiation of vedolizumab. In a shift toward personalization of medicine in IBD, the ability of predictive models for vedolizumab to aid pre-biologic and early management will inform both clinician and patient. Ideally this will provide both a personalized and more cost-effective approach, though further studies in cost-analysis in this framework are needed. Though current models are comprehensive of existing data, future research on microbial and translational biomarkers will be additive and necessary to provide full personalization of treatment.

Keywords: vedolizumab, biologic, response, prediction model, IBD

\section{KEY CONCEPTS}

- Vedolizumab is safe, well-tolerated, and effective.

- UC and CD patients with less severe disease, without prior biologic exposure, and who demonstrate early response to VDZ are most likely to respond to therapy.

- The CDST from Dulai et al. can be used before initiation of VDZ to determine those most likely to respond and those who may be more likely to benefit from early consideration of dose escalation or alternative therapy.

- The CDST from Dulai et al. was able to predict drug exposure, rapidity of onset, and clinical outcomes including clinical and steroid-free remission.

\section{INTRODUCTION}

Vedolizumab (VDZ) is a humanized monoclonal anti-integrin biologic approved for moderate to severe Crohn's Disease (CD) and Ulcerative Colitis (UC). Vedolizumab selectively inhibits leukocyte extravasation into the gut, and few other less clinically relevant tissues, via disruption of alpha4beta7 integrin on leukocytes and adhesion molecules on the vascular endothelium. 
Phase 3 clinical trials confirmed the efficacy of VDZ in CD and UC and observational cohorts have confirmed its real-world effectiveness and safety. Despite the favorable safety profile and effectiveness of VDZ there are no guidelines to aid clinicians with its positioning among biologics. The ushering in of the biologic era brought with it the luxury of greater choice. With multiple options available for therapy in moderate to severe Inflammatory Bowel Diseases (IBD), many of which appear to be equivalent in effectiveness and safety, there has been a necessary push to improve shared-decision making around treatment choices. Hierarchical preferences of providers and patients could bring traditionally second-line therapies to the forefront. With personalization of therapy to these preferences and without formal guidelines or robust comparative clinical trials, it will be increasingly important for clinicians to critically evaluate existing data for many treatment-related factors, including predicting response. In this article we will review current literature from clinical trials, their post-hoc analyses, and realworld data that elucidate predictors of primary response to VDZ in CD and UC.

\section{PREDICTORS OF CLINICAL RESPONSE AND REMISSION}

\section{Baseline Disease Activity}

Subgroup analyses of the GEMINI 1 and 2 trials evaluated demographic and baseline characteristics associated with response and/or remission at 6 and 52 weeks. Less severe clinical disease scores, CDAI score $\leq 330$ and Mayo score $<9$, were associated with higher likelihood of remission compared to placebo at 6 and 52 weeks in CD and UC $(1,2)$. Real-world observational cohorts have supported this finding. The US VICTORY consortium found that those patients with baseline clinically severe $\mathrm{CD}$ or active perianal disease were less likely to obtain clinical remission (3). The French GETAID cohort found that patients with more severe baseline UC or CD were less likely to achieve clinical remission at 14 and 54 weeks $(4,5)$. An Israeli cohort reported that mild clinical disease activity was associated with increased clinical remission in CD at 14 weeks, with no predictors in UC (6). A German cohort of $97 \mathrm{CD}$ patients found that a low Harvey-Bradshaw Index (HBI) score and no hospitalizations in the preceding year predicted clinical remission at 14 weeks (7). In the largest cohort assessed, Chaparro et al. found that higher baseline HBI in CD to be a negative predictor and mild disease in UC to be a positive predictor of clinical remission at 14 weeks (8) (Table 2).

\section{TNF Antagonist Exposure}

It's known that efficacy of TNF antagonists is lower with a second agent after loss of response to a first, and it could be expected that this would be seen with other biologics following TNF antagonist therapy $(9,10)$. In a pooled post-hoc analysis of GEMINI 2 and 3, TNF antagonist naïve patients who had responded to VDZ at 6 weeks were more likely to achieve or maintain remission at week 52 as compared to TNF antagonist failure patients (11) (Table 1). Sands et al. found that patients with CD who had failed TNF antagonist therapy were more likely to be in clinical remission at 10 weeks but not 6 weeks as compared to placebo (26.6 vs. $12.1 \%$
[ $p=0.001]$ and $15.2 \%$ vs. $12.1 \%$ [ $p=0.433]$ ) (14). The VICTORY consortium observed that prior TNF antagonist exposure was associated with lower rates of remission and mucosal healing in $\mathrm{CD}$ and decreased rates of response and remission in $\mathrm{UC}$, and this observation remained irrespective of the statistical approach applied to the data (15). Similarly, results from Stallmach et al. demonstrated that TNF antagonist exposed UC patients were less likely to achieve clinical remission (16). An Israeli cohort in contrast found that prior TNF antagonist exposure had no effect on outcomes of UC or CD at 52 weeks, though limited by low numbers of TNF-naïve patients (8\%) (17) (Table 2).

\section{Concomitant Immunosuppressive Therapy}

The GEMINI trials were not powered to assess combination therapy, however, sub-group analyses did not observe a difference between VDZ monotherapy and combination therapy on rates of response or remission $(1,2)$. Real-world cohorts observed that steroid use was associated with lower rates of response in $\mathrm{CD}(5,6)$ and $\mathrm{UC}(4,16)$, possibly a confounding due to indication as steroids are more often used in patients with more severe disease, but immunomodulator addition after induction was associated with increased response and remission in CD (16). These data did not bear out in remaining real-world cohorts. For example, no differences were noted with any concomitant therapy in Israeli cohorts or the VICTORY or Cross Penine cohorts (3, 17-19). Regardless of these results, it is important to remember that the appeal of the relative safety for VDZ is decreased with combination therapy with corticosteroids and/or immunomodulators (20), and there also does not appear to be the same risk of immunogenicity or benefit of increased trough levels with concomitant immunomodulators for $\operatorname{VDZ}(21,22)$ (Table 2).

\section{Biomarkers}

GEMINI 1 and 2 demonstrated that elevated inflammatory markers were associated with lower rates of clinical response and remission $(1,2)$ and data from real-world cohorts support this finding. A 172 cohort of UC and CD patients from a pair of Boston academic centers observed that rates of remission were lower with elevated CRP (23). The French GETAID cohort shared this finding for patients with UC (5). Stallmach et al. found that an early (week 14) reduction in CRP or fecal calprotectin was associated with higher rates of remission at 54 weeks (16).

However, biomarkers assessed in current trials and real-world cohorts are nonspecific and related to overall disease activity. Battat et al. reviewed novel biomarkers which were postulated to be associated with VDZ response in UC due to their potential relationship to the $\alpha 4 \beta 7$ and adhesion molecule interaction that is inhibited by VDZ (24). At induction, lower soluble TNF was associated with achieving remission. During maintenance, lower soluble VCAM-1 and higher soluble $\alpha 4 \beta 7$ were associated with achieving remission. These results are promising and suggest that novel biomarkers could be incorporated into future studies and prediction models to improve VDZ-specific response prediction (Table 2).

\section{Microbiome}

The gut microbiome is known to be associated with mucosal inflammation in IBD. Ananthakrishnan et al. recruited a 
TABLE 1 | Post-hoc analysis of GEMINI trials.

\begin{tabular}{|c|c|c|}
\hline References & Cohort & Outcomes \\
\hline Feagan et al. (12) & Post-hoc analysis of GEMINI 1 & 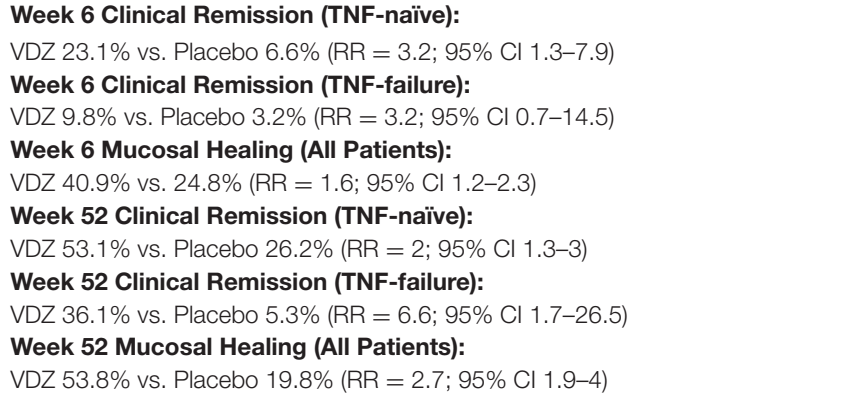 \\
\hline Sands et al. (11) & Post-hoc analysis of GEMINI 2 and 3 & $\begin{array}{l}\text { Week } 6 \text { Clinical Remission (TNF-naïve): } \\
\text { VDZ 12.6\% difference from placebo (95\% Cl 3.7-21.4) } \\
\text { Week } 6 \text { Clinical Remission (TNF-failure): } \\
\text { VDZ } 4.1 \% \text { difference from placebo ( } 95 \% \mathrm{Cl}-1.6-9.8) \\
\text { Week } \mathbf{5 2} \text { Clinical Remission (TNF-naïve): } \\
\text { VDZ } 22.1 \% \text { difference from placebo (95\% Cl 8.9-35.4) } \\
\text { Week } \mathbf{5 2} \text { Clinical Remission (TNF-failure): } \\
\text { VDZ 14.9\% difference from placebo (95\% Cl 4.7-25) }\end{array}$ \\
\hline Sands et al. (13) & Post-hoc analysis of GEMINI 2 and 3 & $\begin{array}{l}\text { GEMINI } 2 \text { Week } 6 \text { Remission: } \\
\text { VDZ+CS 19.0\% vs. Placebo+CS 4.6\% (14.4\% difference; 95\% Cl-1.3-29.6) } \\
\text { VDZ 10.9\% vs. Placebo 8.6\% (without CS) (2.3\% difference; } 95 \% \mathrm{Cl}-6-10.6) \\
\text { GEMINI } 3 \text { Week } 6 \text { Remission: } \\
\text { VDZ+CS } 198 \% \text { vs. Placebo+CS } 10.2 \% \text { (9.6\% difference; } 95 \% \mathrm{Cl} 0.3-19) \\
\text { VDZ 18.6\% vs. Placebo } 14.4 \% \text { (without CS) (4.1\% difference; } 95 \% \mathrm{Cl}-6.3-14.6)\end{array}$ \\
\hline
\end{tabular}

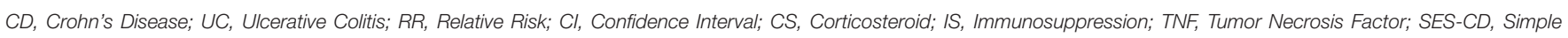
Endoscopic Score for Crohn's Disease; CRP, C-reactive Protein; CDAl, Crohn's Disease Activity Index.

prospective cohort of $42 \mathrm{CD}$ and $43 \mathrm{UC}$ patients receiving VDZ and assessed microbial composition related to disease activity (25). Changes in microbiome diversity were associated with clinical remission in those with CD but not UC. Assessment of biochemical pathways revealed a significant increase in week 14 remission in patients with $\mathrm{CD}$ who had baseline enrichment of BCAA pathways, suggesting a functional component in addition to taxonomic differences as baseline predictors. Of note, the microbial changes of those who achieved remission at week 14 persisted at 1 year, suggesting an early marker rather than a baseline predictor of response. While this study suggests multiple microbial markers of baseline and early predictors of response to VDZ (ie taxonomic differences, diversity, and function) it lacks applicability as microbiome sequencing has not reached clinical point of care. It is also limited by its small, single-center cohort with limited follow-up and assessment of diet and would require further validation; but nonetheless an interesting pilot study to complement the data regarding TNF effect on microbiota and worth further investigation.

\section{PREDICTORS OF ENDOSCOPIC RESPONSE OR REMISSION}

Endoscopic response is an important part of disease assessment and is becoming a larger part of the treatment target in IBD. The recent VERSIFY phase $3 \mathrm{~b}$ clinical trial (26) assessed endoscopic response to VDZ in $\mathrm{CD}$ and found that endoscopic remission rates (SES-CD score $\leq 4)$ were greater in patients naïve to TNF antagonists, those with moderate compared to severe baseline endoscopic disease, and shorter disease duration (26). Endoscopic remission rates at week 26 and 52 were higher in TNF-antagonist naïve (9.6 and 25\%) vs. TNF-antagonist exposure (5.5 and 8.3\%), higher in moderate disease (SES-CD 715) (17 and 20.7\%) vs. severe disease (SES-CD > 15) (6.7 and $14.8 \%)$, and higher in shorter disease duration $(<1$ year) $(37.5$ and $100 \%)$ vs. longer disease duration ( $\geq 7$ years) (7.1 and $11.5 \%)$.

Post-hoc analysis of the GEMINI 1 trial found that mucosal healing rates (Mayo endoscopic subscore of $\leq 1$ ) were higher among VDZ treated patients with UC at 6 weeks $(\mathrm{RR}=1.6 ; 95 \%$ CI $1.2-2.3)$ and 52 weeks ( $R R=2.7 ; 95 \%$ CI 1.9-4) as compared to placebo (12).

The VICTORY cohort evaluated endoscopic response to VDZ in UC and found that $17 \%$ of patients achieved endoscopic remission (Mayo endoscopic sub-score 0) at 12 months. Prior TNF-antagonist was associated with reduced probability of achieving endoscopic response (HR 0.51, 95\% CI 0.29-0.88) (18).

In a Canadian real-world cohort evaluating endoscopic and radiologic remission, VDZ patients with $\mathrm{CD}$ were less likely to obtain objective remission at 6 months (adjusted OR 0.30; 95\% CI: $0.11-0.79, p=0.02$ ) and 12 months (adjusted OR 0.27; 95\% CI: $0.09-0.78, p=0.02$ ) compared to UC (27). There were no differences in rates of remission due to disease severity, previous biologic failure, and pretreatment of CRP. Of note, this study did not separate endoscopic and radiographic remission. 
TABLE 2 | Predictors of clinical response to VDZ from real-world cohorts.

\begin{tabular}{|c|c|c|c|c|}
\hline References & Cohort & Outcomes & $\begin{array}{l}\text { Positive predictors of } \\
\text { response }\end{array}$ & $\begin{array}{l}\text { Negative predictors of } \\
\text { response }\end{array}$ \\
\hline Amiot et al. (4) & $\begin{array}{l}272 \text { patients ( } 161 \mathrm{CD}) \text { with prior } \\
\text { conventional or TNF antagonist } \\
\text { therapy who completed } \\
\text { induction. A multicenter French } \\
\text { cohort }\end{array}$ & $\begin{array}{l}\text { Steroid-free clinical } \\
\text { remission at } 54 \text { weeks }(\mathrm{HBI} \\
\leq 4 \text { or partial Mayo score }<3 \\
\text { with a combined stool } \\
\text { frequency and rectal } \\
\text { bleeding subscore of } \leq 1)\end{array}$ & $\begin{array}{l}\text { CD: Week } 6 \text { response }(O R= \\
7.41 ; 95 \% \mathrm{Cl} 2.85-19.23) \cup C \text { : } \\
\text { Week } 6 \text { response }(O R=7.51 \\
\text { Cl: } 95 \% 3.00-18.88)\end{array}$ & $\begin{array}{l}\text { CD: Corticosteroids at induction } \\
\text { (OR = 0.37; } 95 \% \mathrm{Cl} 0.16-0.88) \text {. } \\
\text { HBI score > } 10 \text { at induction (OR } \\
=0.15 ; 95 \% \mathrm{Cl} 0.06-0.37) \\
\text { UC: WBC }>9000 \times 109 / \mathrm{L}(\mathrm{OR} \\
=0.36 ; 95 \% \mathrm{Cl} 0.14-0.92) . \\
\text { Mayo score }>9 \text { at induction (OR } \\
=0.37 ; 95 \% \mathrm{Cl} 0.15-0.92)\end{array}$ \\
\hline Amiot et al. (5) & $\begin{array}{l}294 \text { patients ( } 173 \mathrm{CD} \text { ) with prior } \\
\text { conventional or TNF antagonist } \\
\text { therapy. A multicenter French } \\
\text { cohort }\end{array}$ & $\begin{array}{l}\text { Steroid-free clinical } \\
\text { remission at } 14 \text { weeks }(\mathrm{HBI} \\
\leq 4 \text { or partial Mayo score }<3 \\
\text { with a combined stool } \\
\text { frequency and rectal } \\
\text { bleeding subscore of } \leq 1)\end{array}$ & $\begin{array}{l}\text { CD: Week } 6 \text { response }(\mathrm{OR}= \\
11.2 ; 95 \% \mathrm{Cl} 4.3-28.8 ; p \\
=<0.001) \cup \mathrm{C}: \text { Week } 6 \\
\text { response }(\mathrm{OR}=5.3 ; 95 \% \mathrm{Cl} \\
2.2-13.1 ; p=<0.001)\end{array}$ & $\begin{array}{l}\mathrm{CD} \text { : Corticosteroid use at } \\
\text { induction }(\mathrm{OR}=0.35 ; 95 \% \mathrm{Cl} \\
0.16-0.77 ; p=0.009) . \mathrm{HBl} \text { score } \\
>10 \text { at induction }(\mathrm{OR}=0.11 \text {; } \\
95 \% \mathrm{Cl} 0.05-0.27 ; p=<0.001) \\
\mathrm{UC}: \mathrm{CRP}>20 \mathrm{mg} / \mathrm{L} \text { at induction } \\
(\mathrm{OR}=0.30 ; 95 \% \mathrm{Cl} 0.11-0.80 ; \\
p=0.02) . \text { Mayo score }>9 \text { at } \\
\text { induction }(\mathrm{OR}=0.21 ; 95 \% \mathrm{Cl} \\
0.08-0.57 ; p=0.002)\end{array}$ \\
\hline
\end{tabular}

Baumgart et al. (7) 212 patients (97 CD) eligible for VDZ. Single site, prospective, German cohort

Chaparro et al. (8)

Dulai et al. (3)

Dulai et al. (18)

Kopylov et al. (6)

Kopylov et al. (17)

Lenti et al. (19)
204 patients (130 CD) treated with VDZ with at least 14 weeks of follow-up from a multicenter Israeli cohort

180 UC patients eligible for VDZ from a multicenter US cohort

193 patients (133 CD) who completed 52 weeks of VDZ treatment with follow-up from a multicenter, retrospective, Israeli cohort

203 patients (135 CD) treated with VDZ from a multicenter UK retrospective cohort

172 patients (107 CD) receiving $\geq 3 \mathrm{VDZ}$ infusions at 2 US academic centers
Clinical remission at 14 Mayo score $\leq 1$ plus a bleeding subscore of 0) Clinical remission at 14 weeks (partial Mayo score $<2$ or $\mathrm{HBI}$ score $<5$ ) resolution of all CD-related symptoms) weeks $(\mathrm{HBI} \leq 4$ or partial

Clinical remission (complete

CD: Low HB score $(p=0.02)$ No hospitalization in prior year $(p=0.01)$ UC: No predictors

UC: Mild vs. severe disease (OR $=6.6$; 95\% Cl 3-14.7)

Clinical remission (complete resolution of all UC-related symptoms) and response (clinically significant response defined as $>50 \%$ reduction in symptom activity by PGA)

Clinical remission at 14 weeks ( $\mathrm{HBI}<5$ and a partial Mayo score $<2$ or SCCAl $<4)$

Clinical remission at 52 weeks $(\mathrm{HBI} \leq 4, \mathrm{CDA}$ $<150$; SCCAl <2, partial Mayo score $\leq 2$ )

Clinical response and remission at 14 and 52 weeks (partial vs. complete/significant symptom relief by PGA)

Clinical response and remission at 14 weeks
CD: Mild clinical activity at induction( $p=0.001)$ UC: no predictors

CD: Clinical response at 14 weeks $(\mathrm{OR}=3.5 ; 95 \%$ Cl 1.4-8.6) UC: Clinical response at 14 weeks $(\mathrm{OR}=7.3 ; 95 \%$ Cl 1.8-29.1)

No predictors
Baseline CRP $>8.0 \mathrm{mg} / \mathrm{L}(\mathrm{OR}=$ 0.33 ; $95 \% \mathrm{Cl} 0.15-0.95 . p=$ 0.04)
CD: Higher baseline $\mathrm{HBI}(\mathrm{OR}=$ 0.6; 95\% Cl 0.5-0.7)

UC: Higher baseline CRP (OR = 0.8; 95\% Cl 0.8-0.9)

Prior TNF-antagonist exposure $(\mathrm{HR}=0.40$; 95\% Cl 0.20-0.81)

Active or historical smoking (HR $=0.47$; 95\% Cl 0.25-0.89) Active perianal disease $(H R=$ 0.49; 95\% Cl 0.27-0.88) Severe disease activity (HR 0.54; 95\% Cl: 0.31-0.95)

Achieve response with prior TNFantagonist exposure ( $\mathrm{HR}, 0.58$; 95\% Cl, 0.39-0.86)

Achieve remission with prior TNF-antagonist exposure (HR, 0.55; 95\% Cl, 0.35-0.88) 
TABLE 2 | Continued

\begin{tabular}{|c|c|c|c|c|}
\hline References & Cohort & Outcomes & $\begin{array}{l}\text { Positive predictors of } \\
\text { response }\end{array}$ & $\begin{array}{l}\text { Negative predictors of } \\
\text { response }\end{array}$ \\
\hline Stallmach et al. (16) & $\begin{array}{l}127 \text { patients }(67 \mathrm{CD} \text { ) eligible for } \\
\text { VDZ from a single site, } \\
\text { prospective German cohort }\end{array}$ & $\begin{array}{l}\text { Clinical remission at } 54 \\
\text { weeks }(\mathrm{HBI} \leq 4 \text { or a partial } \\
\text { Mayo score } \leq 1 \text { with a } \\
\text { bleeding subscore of } 0 \text { ) }\end{array}$ & $\begin{array}{l}\text { CD: Response or remission at } \\
\text { week } 14 \text { ( } p=<0.001) \text {. Lower } \\
\text { CRP at week } 14 \text { as compared to } \\
\text { baseline }(p=0.01) \cup C \text { : } \\
\text { Remission at week } 14(p= \\
<0.0001) \text {. No prior TNF } \\
\text { antagonist treatment (OR }=5.3 \text {; } \\
95 \% \mathrm{Cl} 1.3-21.4) \text {. Less than } \\
25 \% \text { use of steroids within prior } \\
6 \text { months (OR }=5.4 ; 95 \% \mathrm{Cl} \\
1.3-22.1) \text {. Lower CRP at week } \\
14 \text { as compared to baseline }(p= \\
0.003) \text {. Lower fecal calprotectin } \\
\text { at week } 14(p=0.002)\end{array}$ & \\
\hline
\end{tabular}

CD, Crohn's Disease; UC, Ulcerative Colitis; OR, Odds Ratio; HR, Hazard Ratio; Cl, Confidence Interval; HBI, Harvey-Bradshaw Index; SCCAI, Simple Clinical Colitis Activity Index; CRP, C-reactive Protein; CDAl, Crohn's Disease Activity Index; PGA, Physician's Global Assessment.

\section{PREDICTORS OF ADVERSE EVENTS}

Colombel et al. provided an integrated VDZ clinical trial analysis from the GEMINI trials and their follow-up long-term safety data (>4000 PYs) (28). They found VDZ to be well-tolerated with an acceptable safety profile. Overall, patients with UC and CD exposed to VDZ had less adverse events (AE) than placebo when adjusted for exposure (247.8/100 vs. 419.4/100 PYs). This included infectious AEs, with overall incidence in VDZ-exposed being lower than placebo (63.5/100 vs. $82.9 / 100$ PYs). Due to the gut-selective mechanism of action of VDZ there may be concern that these patients are at higher risk for enteric infections. However, the rates of enteric infections were very low $(\leq 0.8 / 100$ PYs), excluding gastroenteritis. Predictors of serious infection in total cohort of UC and CD were younger age, opioid use, and corticosteroid use. When separated by type of IBD, prior TNF-antagonist failure was found to be a predictor of serious infection in the UC cohort but not younger age or concomitant steroid use.

In our analysis of real-world data from the VICTORY cohort, we also found VDZ to be well-tolerated with a similar safety profile to the GEMINI trials (20). Predictors of infection included active smoker status and number of concomitant immunosuppressive agents. VDZ monotherapy and VDZ plus immunomodulator had comparable rates of AEs (5.9/100 vs. 5.8/100 PYE), but the addition of corticosteroids to either resulted in increased risk of infection in an incremental fashion (VDZ+CS 9.5/100 PYE vs. VDZ+IM+CS 12/100 PYE). This is important to note and discuss with patients as the gutselective mechanism of VDZ is thought to convey this favorable safety profile which cannot be relied on with the addition of other immunosuppressants.

\section{PREDICTION MODELING}

There are many potential predictors of response that have been identified from clinical trial and real-world data (see Tables 1, 2 for summary), however, translating these findings into clinical practice can be challenging. The ability to cluster these data into a tool that can inform patients and clinicians about potential response early in treatment course, or ideally before starting, would allow for greater personalization within IBD therapy. Waljee et al. and Dulai et al. have both developed prediction models of response from post-hoc analyses of the GEMINI trials to address this need. Although both used a similar dataset for model derivation, differences exist between them which are important to highlight.

First, Waljee et al. utilized a machine-learning approach that incorporated baseline patient characteristics and labs in combination with changes in lab values during induction (29, 30). Our group in contrast used regression methodology with a primary focus on baseline patient characteristics and labs $(31,32)$. This distinction is important because the machinelearning model therefore requires a trial of induction therapy prior to determining if a patient is likely to respond to VDZ whereas baseline regression models can help classify patients before treatment initiation thereby avoiding the need to prove a lack of response or sub-optimal response after induction. Second, both groups used corticosteroid-free clinical remission and endoscopic remission as dependent outcomes for CD and UC, but our model also incorporated predictors of clinical remission and durable remission for $\mathrm{CD}$ into the assessment. Third, both groups transformed these models into clinical decision support tools (CDST) with Waljee et al. creating a simplified equation using variable importance plots and our group creating a point scoring system based CDST. Fourth, although both models demonstrated modest accuracy and performance within the GEMINI cohort, only the regression models underwent external validation in routine practice cohorts of patients treated with VDZ. Finally, the regression-based prediction models and CDSTs have now been shown to be able to predict not only clinical and endoscopic effectiveness, but also rapidity of treatment response, measured drug exposure, and biomarker response; thereby providing a more comprehensive prediction of key 
TABLE 3 | Prediction models.

Regression Models (Dulai)

CD

UC

Derivation-GEMINI Cohorts

\begin{tabular}{ll}
\hline Performance & Week 26 CREM AUROC 0.69 Week 26 CSF-REM \\
& AUROC 0.68 \\
$\begin{array}{l}\text { Validation-VICTORY Cohorts } \\
\text { Primary Outcome }\end{array}$ & Clinical and Endoscopic Remission at Week 26 \\
& \\
Performance & Week 26 CREM AUROC 0.67 \\
& Week 26 CSF-REM AUROC 0.66 \\
& Week 26 Mucosal Healing AUROC 0.72 Week \\
& 26 Deep remission AUROC 0.73 \\
& Week 26 CF-REM with MH AUROC 0.75
\end{tabular}

$\begin{array}{ll} & \text { MH Specificity: } 30 \% \\ & \text { CSF-DR Sensitivity: } 100 \% \\ & \text { CSF-DR Specificity: } 31 \% \\ & \mathbf{1 9} \text { points: } \\ & \text { CREM Sensitivity: } 33 \% \\ & \text { CREM Specificity: } 80 \% \\ & \text { CSF-REM Sensitivity: } 37 \% \\ & \text { CSF-REM Specificity: } 77 \% \\ & \text { MH Sensitivity: } 40 \% \\ & \text { MH Specificity: } 80 \% \\ & \text { CSF-DR Sensitivity: } 46 \% \\ \text { POC Transformation } & \text { CSF-DR Specificity: } 78 \% \\ \text { Absence of prior TNF antagonist exposure (+3 points) } & \\ \text { Absence of prior bowel surgery (+2 points) } & \\ \text { Absence of prior fistulizing disease (+2 points) } & \\ \text { Baseline level of albumin (+0.4 points per g/L) } & \\ \text { Baseline concentration of C-reactive protein (reduction of } 0.5 \text { points for values } \\ \text { between } 3.0 \text { and } 10.0 \text { mg/L and } 3.0 \text { points for values }>10.0 \text { mg/L) }\end{array}$

Sensitivity/Specificity $(95 \% \mathrm{Cl})$ of CDST at Week 26

\section{3 points:}

CREM Sensitivity: $92 \%$

CREM Specificity: 25\%

CSF-REM Sensitivity: $94 \%$

CSF-REM Specificity: $30 \%$

MH Sensitivity: $98 \%$

MH Specificity: $30 \%$

CSF-DR Sensitivity: 100\%

CSF-DR Specificity: $31 \%$

points:

CSF-REM Sensitivity: $37 \%$

Specificity: $77 \%$

CSF-DR Sensitivity: 46\% (19-75\%);

CSF-DR Specificity: 78\% (69-85\%)

Absence of prior bowel surgery ( +2 points)

Baseline concentration of $\mathrm{C}$-reactive protein (reduction of 0.5 points for values

between 3.0 and $10.0 \mathrm{mg} / \mathrm{L}$ and 3.0 points for values $>10.0 \mathrm{mg} / \mathrm{L}$ )
Week 52 CSF-REM AUROC 0.69

Sensitivity/Specificity $(95 \% \mathrm{Cl})$ of CDST at Week 26

\section{6 points:}

CSF-REM Sensitivity: $93 \%$

CSF-REM Specificity: 15\% $\mathbf{3 2}$ points:

CSF-REM Sensitivity: $51 \%$

CSF-REM Specificity: $68 \%$
Absence of prior TNF antagonist exposure $(+3$ points)

Disease duration $\geq 2$ years ( +3 points)

Baseline endoscopic activity (moderate vs. severe) (+2 points)

Baseline albumin concentration $(+0.65$ points per $\mathrm{g} / \mathrm{L})$

\section{Secondary Outcomes from Dulai Prediction Models}

\begin{tabular}{|c|c|c|c|c|c|c|}
\hline & & & Low probability & Intermediate probability & High probability & $p$-value \\
\hline \multirow[t]{7}{*}{ Drug exposure } & \multicolumn{6}{|c|}{ Pre-Dose VDZ Concentrations (ug/mL) by Probability of Response } \\
\hline & \multirow[t]{2}{*}{ Week 2} & UC & 22.9 & 27.4 & 32 & $<0.001$ \\
\hline & & $C D$ & 24.7 & 28.45 & 32.7 & $<0.001$ \\
\hline & \multirow[t]{2}{*}{ Week 6} & UC & 17.2 & 23.5 & 34.9 & $<0.001$ \\
\hline & & $C D$ & 15.3 & 23.5 & 33.4 & $<0.001$ \\
\hline & \multirow[t]{2}{*}{ Week 46} & UC & 22.5 & 27.8 & 31.5 & 0.016 \\
\hline & & $C D$ & 18.7 & 25.8 & 32.6 & 0.0008 \\
\hline \multirow[t]{6}{*}{ Onset of action } & \multicolumn{6}{|c|}{ Change in Partial Mayo Score (UC) or Harvey-Bradshaw Index (CD) from Baseline by Probability of Response } \\
\hline & \multirow[t]{2}{*}{ Week 6} & UC & -1.22 & -1.89 & -2.21 & $<0.001$ \\
\hline & & $C D$ & -1.69 & -2.61 & -4.22 & $<0.001$ \\
\hline & Week 38 & $C D$ & -4.62 & -5.57 & -6.76 & $<0.001$ \\
\hline & \multirow[t]{2}{*}{ Week 52} & UC & -3.64 & -4.42 & -4.33 & 0.029 \\
\hline & & $C D$ & -4.68 & -6.32 & -7.17 & $<0.001$ \\
\hline
\end{tabular}

AUROC, Area Under Receiver Operator Curse; CSFR, Corticosteroid-Free Remission; CSFER, Corticosteroid-Free Endoscopic Remission; CREM, Clinical Remission; CSF-REM, Corticosteroid-free Remission; MH, Mucosal Healing; DR, Deep Remission.

Dulai et al. CDST for CD Probability of response: Low (Intermediate $\leq 13$ ), Intermediate ( $>13$ to $\leq 19$ points), High (>19 points).

Dulai et al. CDST for UC Probability of response: Low ( $\leq 26$ points), Intermediate ( $>26$ to $\leq 32$ points), High ( $>32$ points). 
components to patient outcomes and opportunities for treatment optimization (Table 3 ).

\section{FUTURE}

Novel comparative head-to-head trials are forthcoming with the first such trial recently published. The VARSITY trial directly compared Vedolizumab vs. Adalimumab (ADA) as maintenance therapy in UC (33). Clinical remission rates at 52 weeks were $31.3 \%$ vs. $22.5 \%$ in VDZ vs. $\mathrm{ADA}(95 \% \mathrm{CI}, 2.5-15.0 ; p=0.006)$ and 52 week endoscopic improvement rates of $39.7 \%$ vs. $27.7 \%$ (95\% CI, 5.3-18.5; $p<0.001$ ). Rates of serious infections were low and similar between cohorts. This trial shows that VDZ is superior to ADA in achieving clinical remission and endoscopic improvement at 52 weeks maintenance therapy. Similar trials are sure to follow which will further inform on biologic positioning while adding more data to interpret predictors of response.

\section{CONCLUSION}

VDZ is known to be safe, well tolerated, and effective. These are important points for personalization, but can we predict

\section{REFERENCES}

1. Sandborn WJ, Feagan BG, Rutgeerts P, Hanauer S, Colombel JF, Sands BE, et al. Vedolizumab as induction and maintenance therapy for Crohn's disease. N Engl J Med. (2013) 369:711-21. doi: 10.1056/NEJMoa1215739

2. Feagan BG, Rutgeerts P, Sands BE, Hanauer S, Colombel JF, Sandborn WJ, et al. Vedolizumab as induction and maintenance therapy for ulcerative colitis. N Engl J Med. (2013) 369:699-710. doi: 10.1056/NEJMoa1215734

3. Dulai PS, Singh S, Jiang X, Peerani F, Narula N, Chaudrey K, et al. The realworld effectiveness and safety of vedolizumab for moderate-severe crohn's disease: results from the US VICTORY consortium. Am J Gastroenterol. (2016) 111:1147-55. doi: 10.1038/ajg.2016.236

4. Amiot A, Serrero M, Peyrin-Biroulet L, Filippi J, Pariente B, Roblin X, et al. One-year effectiveness and safety of vedolizumab therapy for inflammatory bowel disease: a prospective multicentre cohort study. Aliment Pharmacol Therapeut. (2017) 46:310-21. doi: 10.1111/apt.14167

5. Amiot A, Grimaud JC, Peyrin-Biroulet L, Filippi J, Pariente B, Roblin X, et al. Effectiveness and safety of vedolizumab induction therapy for patients with inflammatory bowel disease. Clin Gastroenterol. (2016) 14:1593-601.e2. doi: 10.1016/j.cgh.2016.02.016

6. Kopylov U, Ron Y, Avni-Biron I, Koslowsky B, Waterman M, Daher S, et al. Efficacy and safety of vedolizumab for induction of remission in inflammatory bowel disease-the israeli real-world experience. Inflamm Bowel Dis. (2017) 23:404-8. doi: 10.1097/MIB.0000000000001039

7. Baumgart DC, Bokemeyer B, Drabik A, Stallmach A, Schreiber S. Vedolizumab induction therapy for inflammatory bowel disease in clinical practice-a nationwide consecutive German cohort study. Aliment Pharmacol Therapeut. (2016) 43:1090-102. doi: 10.1111/apt.13594

8. Chaparro M, Garre A, Ricart E, Iborra M, Mesonero F, Vera I, et al. Short and long-term effectiveness and safety of vedolizumab in inflammatory bowel disease: results from the ENEIDA registry. Aliment Pharmacol Therapeut. (2018). 48:839-51. doi: 10.1111/apt.14930

9. Gisbert JP, Marin AC, McNicholl AG, Chaparro M. Systematic review with meta-analysis: the efficacy of a second anti-TNF in patients with inflammatory bowel disease whose previous anti-TNF treatment has failed. Aliment Pharmacol Therapeut. (2015) 41:613-23. doi: 10.1111/apt. 13083

10. Sandborn WJ, Rutgeerts P, Enns R, Hanauer SB, Colombel JF, Panaccione R, et al. Adalimumab induction therapy for Crohn disease previously treated response to further guide therapy and shared decision-making? Subgroup analyses from the GEMINI trials were not powered for this question but they do provide evidence supplemented by real-world observational studies that increase generalizability for a heterogenous IBD population. Overall, it appears that patients with less severe disease (clinical, biomarkers) without prior biologic exposure and who demonstrate early response to VDZ have the highest rates of durable clinical and endoscopic response and remission. Prediction models and CDST confirmed these predictors and can be utilized to identify patients with higher probability of nonresponse so that either before initiation or after a short duration of treatment a decision to continue, discontinue, or even dose-escalation would be more informed. As biologics have become a mainstay of therapy, cost-analysis will help determine if prediction modeling can improve costeffectiveness of VDZ by determining responders, nonresponders, and those with response latency needing dose escalation.

\section{AUTHOR CONTRIBUTIONS}

All authors listed have made a substantial, direct and intellectual contribution to the work, and approved it for publication.

with infliximab: a randomized trial. Ann Int Med. (2007) 146:829-38. doi: 10.7326/0003-4819-146-12-200706190-00159

11. Sands BE, Sandborn WJ, Van Assche G, Lukas M, Xu J, James A, et al. Vedolizumab as induction and maintenance therapy for Crohn's disease in patients naive to or who have failed tumor necrosis factor antagonist therapy. Inflamm Bowel Dis. (2017) 23:97-106. doi: 10.1097/MIB.0000000000 000979

12. Feagan BG, Rubin DT, Danese S, Vermeire S, Abhyankar B, Sankoh $S$, et al. Efficacy of vedolizumab induction and maintenance therapy in patients with ulcerative colitis, regardless of prior exposure to tumor necrosis factor antagonists. Clin Gastroenterol. Hepatol. (2017) 15:229-39.e5. doi: 10.1016/j.cgh.2016.08.044

13. Sands BE, Van Assche G, Tudor D, Akhundova-Unadkat G, Curtis RI, Tan T. Vedolizumab in combination with corticosteroids for induction therapy in crohn's disease: a post hoc analysis of GEMINI 2 and 3. Inflamm Bowel Dis. (2019) 25:1375-82. doi: 10.1093/ibd/izy384

14. Sands BE, Feagan BG, Rutgeerts P, Colombel JF, Sandborn WJ, Sy R, et al. Effects of vedolizumab induction therapy for patients with Crohn's disease in whom tumor necrosis factor antagonist treatment failed. Gastroenterology. (2014) 147:618-27.e3. doi: 10.1053/j.gastro.2014.05.008

15. Narula N, Peerani F, Meserve J, Kochhar G, Chaudrey K, Hartke J, et al. Vedolizumab for ulcerative colitis: treatment outcomes from the VICTORY consortium. Am J Gastroenterol. (2018) 113:1345. doi: 10.1038/s41395-018-0162-0

16. Stallmach A, Langbein C, Atreya R, Bruns T, Dignass A, Ende K, et al. Vedolizumab provides clinical benefit over 1 year in patients with active inflammatory bowel disease - a prospective multicenter observational study. Aliment Pharmacol Therapeut. (2016) 44:1199-212. doi: 10.1111/apt.13813

17. Kopylov U, Avni-Biron I, Ron Y, Koslowsky B, Waterman M, Daher S, et al. Effectiveness and safety of vedolizumab for maintenance treatment in inflammatory bowel disease-The Israeli real world experience. Digest Liver Dis. (2019) 51:68-74. doi: 10.1016/j.dld.2018.07.040

18. Dulai P Meserve JD, Hartke JG, Chilukuri P, Chaudrey K, KolianiPace JL, et al. Predictors of clinical and endoscopic response with vedolizumab for the treatment of moderately-severely active ulcerative colitis: results from the US victory consortium. Gastroenterology. (2017) 152:S371. doi: 10.1016/S0016-5085(17)31488-9

19. Lenti MV, Levison S, Eliadou E, Willert R, Kemp K, Carter A, et al. A realworld, long-term experience on effectiveness and safety of vedolizumab in 
adult patients with inflammatory bowel disease: the cross pennine study. Digest Liver Dis. (2018) 50:1299-304. doi: 10.1016/j.dld.2018.07.007

20. Meserve J, Aniwan S, Koliani-Pace JL, Shashi P, Weiss A, Faleck D, et al. Retrospective analysis of safety of vedolizumab in patients with inflammatory bowel diseases. Clin Gastroenterol. (2019) 17:1533-40.e2. doi: 10.1016/j.cgh.2018.09.035

21. Rosario M, Dirks NL, Milch C, Parikh A, Bargfrede M, Wyant T, et al. A review of the clinical pharmacokinetics, pharmacodynamics, and immunogenicity of vedolizumab. Clin Pharmacokinet. (2017) 56:1287-301. doi: 10.1007/s40262-017-0546-0

22. Bian S, Dreesen E, Tang HT, Compernolle G, Peeters M, Van Assche $\mathrm{G}$, et al. Antibodies toward vedolizumab appear from the first infusion onward and disappear over time. Inflamm Bowel Dis. (2017) 23:2202-8. doi: 10.1097/MIB.0000000000001255

23. Shelton E, Allegretti JR, Stevens B, Lucci M, Khalili H, Nguyen DD, et al. Efficacy of vedolizumab as induction therapy in refractory IBD patients: a multicenter cohort. Inflamm Bowel Dis. (2015) 21:2879-85. doi: 10.1097/MIB.0000000000000561

24. Battat R, Dulai PS, Vande Casteele N, Evans E, Hester KD, Webster E, et al. Biomarkers are associated with clinical and endoscopic outcomes with vedolizumab treatment in ulcerative colitis. Inflamm Bowel Dis. (2019) 25:410-20. doi: 10.1093/ibd/izy307

25. Ananthakrishnan AN, Luo C, Yajnik V, Khalili H, Garber JJ, Stevens BW, et al. Gut microbiome function predicts response to anti-integrin biologic therapy in inflammatory bowel diseases. Cell Host Microbe. (2017) 21:603-10.e3. doi: 10.1016/j.chom.2017.04.010

26. Danese S, Sandborn WJ, Colombel JF, Vermeire S, Glover SC, Rimola J, et al. Endoscopic, radiologic, and histologic healing with vedolizumab in patients with active Crohn's disease. Gastroenterology. (2019) 157:1007-18.e7. doi: 10.1053/j.gastro.2019.06.038

27. Kotze PG, Ma C, Almutairdi A, Al-Darmaki A, Devlin SM, Kaplan GG, et al. Real-world clinical, endoscopic and radiographic efficacy of vedolizumab for the treatment of inflammatory bowel disease. Aliment Pharmacol Therapeut. (2018) 48:626-37. doi: 10.1111/apt.14919

28. Colombel JF, Sands BE, Rutgeerts P, Sandborn W, Danese S, D'Haens G, et al. The safety of vedolizumab for ulcerative colitis and Crohn's disease. Gut. (2017) 66:839-51. doi: 10.1136/gutjnl-2015-311079
29. Waljee AK, Liu B, Sauder K, Zhu J, Govani SM, Stidham RW, et al. Predicting corticosteroid-free biologic remission with vedolizumab in Crohn's disease. Inflamm Bowel Dis. (2018) 24:1185-92. doi: 10.1093/ibd/izy031

30. Waljee AK, Liu B, Sauder K, Zhu J, Govani SM, Stidham RW, et al. Predicting corticosteroid-free endoscopic remission with vedolizumab in ulcerative colitis. Aliment Pharmacol Therapeut. (2018) 47:763-72. doi: 10.1111/apt.14510

31. Dulai PS, Boland BS, Singh S, Chaudrey K, Koliani-Pace JL, Kochhar $\mathrm{G}$, et al. Development and validation of a scoring system to predict outcomes of vedolizumab treatment in patients with Crohn's disease. Gastroenterology. (2018) 155:687-95.e10. doi: 10.1053/j.gastro.2018. 05.039

32. Dulai PS, Singh S, Casteele NV, Meserve J, Winters AC, Chablaney S, et al. Development and validation of clinical scoring tool to predict outcomes of treatment with vedolizumab in patients with ulcerative colitis. Clin Gastroenterol Hepatol. (2020) pii:S1542-3565(20)30174-9. doi: 10.1016/j.cgh.2020.02.010

33. Sands BE, Peyrin-Biroulet L, Loftus EV Jr, Danese S, Colombel JF, Toruner M, et al. Vedolizumab versus adalimumab for moderate-to-severe ulcerative colitis. N Engl J Med. (2019) 381:1215-26. doi: 10.1056/NEJMoa 1905725

Conflict of Interest: PD is supported by an American Gastroenterology Association Research Scholar Award. PD has served as a consultant for Abbvie, Takeda, Pfizer, Janssen and received research support from Abbvie, Takeda, Pfizer, Janssen.

The remaining author declares that the research was conducted in the absence of any commercial or financial relationships that could be construed as a potential conflict of interest.

Copyright $(02020$ Meserve and Dulai. This is an open-access article distributed under the terms of the Creative Commons Attribution License (CC BY). The use, distribution or reproduction in other forums is permitted, provided the original author(s) and the copyright owner(s) are credited and that the original publication in this journal is cited, in accordance with accepted academic practice. No use, distribution or reproduction is permitted which does not comply with these terms. 